\section{CARA PERNAFASAN DAN GERAK TORSO DALAM TARI GOLEK MENAK YOGYAKARTA}

\section{Sarjiwo}

Jurusan Seni Tari Fakultas Seni Pertunjukan ISI Yogyakarta

\section{Abstract}

The way of breath taking and torso movement are the esthetic characteristic of Yogyakartan Golek Menak dance. This dance, which was created by Sri Sultan Hamengku Buwono IX, is a dance inspired by Golek Menak puppet played by a dalang (the puppet player). The dance movement became a reference of Golek Menak Dance.

The movement characteristic of Golek Menak puppet taken by Golek Menak dance is unjal ambegan (a way of taking a breath). Every dancer has to master that movement to be applied in every movement activity. However, not every dancer can do it well because unjal ambegan must be followed by torso movement to emphasize the movement so that the dance becomes beautiful. Therefore, unjal ambegan is not only a way of breath taking but also two body activities interrelated, not able to be independent. Both are ways of breath taking involving torso movement.

Key words: Golek Menak dance, unjal ambegan, torso movement

\section{A. Pendahuluan}

Sudah cukup lama di Yogyakarta ada pementasan Tari Golek Menak dalam satu fragmen penuh dengan melibatkan jumlah penari yang banyak. Pementasan terakhir terjadi pada 1998 ketika Pamulangan Beksa Sasminta Mardawa mementaskan fragmen dengan lakon Kelaswara Palakrama di Bangsal Kepatihan Yogyakarta. Pergelaran yang diadakan sebagai penghormatan dan peringatan 1000 hari meninggalnya KRT Sasmintadipura. Lakon Kelaswara Palakrama merupakan lakon yang disutradarai Rama Sas (panggilan untuk KRT Sasminta Dipura) pada 1989 pada saat pementasan pembakuan Tari Golek Menak di tempat yang sama. Sebagai empu tari klasik Yogyakarta, Rama Sas merupakan salah seorang yang terlibat dalam pembakuan Tari Golek Menak.

Tari Golek Menak dalam bentuk pethilan, misalnya Beksan Menak Putri atau pun putra masih dapat disaksikan dalam even pesta pernikahan atau pun penyambutan tamu. Kraton Yogyakarta misalnya, apabila menjamu tamu Tari Golek Menak menjadi salah satu pilihan yang menyertai acara makan malam. Biasanya pilihan jatuh pada Beksan Menak Putri dengan menaiki garuda, di antaranya adalah Beksan Menak Putri Kelaswara Adaninggar, Sudarawert Sirtupilaeli, atau Beksan Menak Putra Umarmaya Umarmadi. Jenis beksan itu yang menjadi pilihan. Oleh karena itu, ketika dalam acara peringatan Dies Natalis UNY ke-43, yang di dalam prosesi masuknya anggota senat didahului dengan pergelaran tari dengan orientasi gerak mengambil dari motif-motif gerak dari Tari Golek Menak menjadi sangat menarik.

Pada saat gladi bersih ada seseorang yang bertanya kepada penulis, kenapa gerak-gerak yang dilakukan penari sebagian besar kurang manteb. Pertanyaan ini memicu penulis untuk menuliskan pengalaman penulis selama mengikuti proses perjalanan penyempurnaan Tari Golek Menak bersama tokohtokoh tari Yogyakarta yang ditunjuk oleh Sri Sultan Hamengkubuwana IX pada waktu itu. Apalagi perjalanan Tari Golek Menak ini tergolong lebih muda dibandingkan tari klasik Yogyakarta.

Tari klasik Yogyakarta yang telah mempunyai aturan-aturan baku dan mapan telah dipahami bersama oleh para pelaku tari. Tetapi, Tari Golek Menak setelah disempurnakan dan dibakukan motif geraknya, kelihatannya kurang dimengerti oleh mereka yang tidak terlibat secara langsung dalam proses pembakuan itu. Apalagi hasil penyempurnaan dan pembakuan tidak diikuti dengan sosialisasi hasilnya dengan workshop misalnya. Maka, ketika penulis menyaksikan pergelaran tari pada Dies Natalis UNY ke-43 tersebut sangat tampak adanya teknik gerak yang menjadi ciri khas Tari Golek Menak yang belum dikuasai dengan baik oleh para penarinya. Tentu hal itu tidak hanya ditemui pada acara tersebut. Masih banyak di luar even itu yang para penarinya belum dapat melakukannya dengan baik. Hal yang menjadi ciri dalam Tari Golek Menak tersebut adalah gerak "unjal ambegan".

\section{B. Latar Belakang Pembakuan Tari Golek Menak}

Tari Golek Menak, juga sering disebut Beksan Golek Menak ciptaan Sri Sultan Hamengku Buwono IX, adalah sebuah karya tari hasil adaptasi dari wayang golek menak dari Kedu yang disaksikan Sri Sultan Hamengku Buwana IX pada 1941. Berdasarkan pengamatan tersebut, gerak-gerak yang ada pada wayang golek diadaptasikan ke dalam Tari Golek Menak.

Ada hal yang menarik dari adaptasi itu, yakni adanya ciri khas yang diambil dari wayang golek ketika boneka/wayang sedang dimainkan oleh dalang. Ciri tersebut yaitu adanya gerak unjal ambegan (menarik nafas) yang mampu memberi kesan hidup pada boneka wayang. Kesan itu ditangkap menjadi kesan estetis yang selanjutnya dipakai sebagai ciri dalam Tari Golek Menak. Apabila ciri dari aktivitas gerak itu mampu dilakukan dengan baik oleh penari golek menak, maka tokoh yang dimainkannya akan menjadi "hidup".

Pada sarasehan di Anjungan DIY Taman Mini Indonesia Indah Jakarta (29 Desember 1987), Sri Sultan Hamengku Buwana IX menyampaikan bahwa Tari Golek Menak sudah berkembang jauh meskipun belum bisa seperti apa yang diharapkan. Berangkat dari pemikiran tersebut, pada 30 Desember 1987 dibentuk tim yang bertugas menyempurnakan Tari Golek Menak. 
Tim tersebut terdiri atas enam organisasi dan lembaga kesenian yang ada di Yogyakarta, yakni Pamulangan Beksa Mardawa Budaya, Siswo Among Bekso, Paguyuban Surya Kencana, PLT Bagong Kussudiardja, SMKI Yogyakarta, dan Institut Seni Indonesia Yogyakarta. Sedangkan tokoh dari keenam lembaga tersebut adalah KRT Sasmintadipura (alm./seorang empu tari klasik Yogyakarta yang dedikasinya pada tari klasik Yogyakarta tidak diragukan lagi), RM Dinusatomo (pimpinan Yayasan Siswo Among Bekso Yogyakarta), RM Ywanjono (pimpinan Paguyuban Suryo Kencana Yogyakarta, putra dari tokoh tari klasik gaya Yogyakarta GBPH Suryobrongto), Bagong Kussudiardjo (alm./seorang kreator tari yang sudah sangat dikenal di dunia tari), Sunartomo (pamong/guru di SMKI Negeri Yogyakarta dan kini menjadi abdi dalem Kraton Yogayakarta dengan nama KRT Condroradono), dan Bambang Pujasworo, S.S.T., M.Hum. (seorang penari alus, dosen di Jurusan Seni Tari Fakultas Seni Pertunjukan ISI Yogyakarta, putra dari Sudarso Pringgobroto salah seorang pendiri Akademi Seni Tari Indonesia Yogyakarta).

Setelah melalui proses yang panjang, hasil penyempurnaan tersebut dipentaskan pada 17 Maret 1989 di Bangsal Kepatihan Yogyakarta. Selanjutnya, dilakukan pentas ulang pada 4 September 1993 di Anjungan DIY Taman Mini Indonesia Indah Jakarta tempat awal mula gagasan penyempurnaan itu dicanangkan. Dari kerja tim penyempurna tersebut dihasilkan beberapa tipe karakter yang telah dibakukan motif geraknya, meski hasil penyempurnaan itu tidak sempat disaksikan Sri Sultan Hamengku Buwono IX selaku penggagas dan penciptannya karena keburu wafat pada 3 Oktober 1988

Wafat Sri Sultan Hamengku Buwono IX sebelum menyaksikan hasil penyempurnaan, menjadikan posisi hasil penyempurnaan terasa dalam posisi mengambang atau seakan belum disahkan. Sebagai penggagas serta pencipta dari Tari Golek Menak, tentunya "sabda"-nya sangat diharapkan. Karena, pada dasarnya para tokoh yang terlibat dalam penyempurnaan sekedar merealisasikan gagasannya dalam menyempurnakan Tari Golek Menak. Oleh karena itu, dengan tidak/belum adanya pengakuan atau pengesahan dari Sri Sultan Hamengku Buwono IX, hasil upaya itu menjadi terasa hampa. Apalagi, tidak adanya pelatihan-pelatihan lanjutan untuk menyosialisasikan hasil penyempurnaan mengakibatkan motif-motif yang telah disepakati itu kurang dikuasai oleh sebagian besar penari klasik gaya Yogyakarta.

Akibat dari yang tersebut di atas, beberapa perkumpulan pendukung penyempurnaan ada yang kembali ke gaya sebelum diadakannya penyempurnaan. Namun, dari hasil wawancara dengan semua tokoh yang diberi mandat untuk penyempurnaan itu mempunyai pendapat yang sama tentang ciri di dalam Tar Golek Menak, yaitu gerak unjal ambegan. Ciri yang mampu memberi kesan "hidup" bagi penari yang mampu melakukannya.
Kemampuan untuk dapat melakukan gerak menjadi "hidup" tidak dimiliki oleh setiap penari Golek Menak. Hal itu disebabkan aktivitas tersebut tidak dapat dideskripsikan dan berlaku untuk semua penari. Artinya, di dalam bergerak setiap penari mempunyai kemampuan individual yang berbeda satu dengan yang lain. Memang, unjal ambegan dapat diartikan sebagai cara menarik nafas. Tetapi, untuk dapat memberi kesan "hidup", tentu tidak sekedar menarik nafas sebagaimana pernafasan sehari-hari. Unjal ambegan di sini harus pula diikuti oleh kemampuan menggerakkan torso di dalam memberikan penegasan gerak. Kemampuan mengoordinasikan keduanya diperlukan agar tarian yang dibawakan menjadi baik, indah, yang pada akhirnya akan lebih "hidup". Pengertian "hidup" di sini dapat diartikan sebagai kandungan estetika di dalam Tari Golek Menak. Tentu, tidak mengesampingkan aspek lain yang menyertainya untuk menjadi indah dan hidup.

\section{Tentang Gerak “Unjal Ambegan"}

Gerak unjal ambegan adalah gerak yang diakibatkan dari cara menarik nafas dengan akibat gerak pada torso. Gerak itu merupakan ciri khas Tari Golek Menak sejak awal terciptanya sampai dewasa ini. Sebagaimana telah dipaparkan di atas bahwa Tari Golek Menak diciptakan atas inspirasi dari boneka/wayang golek menak yang sedang dimainkan oleh dalang. Oleh karena itu, gerak-gerak pada boneka atau wayang golek menjadi acuan di dalam Tari Golek Menak. Sebagai benda mati, boneka/wayang golek hanya bisa dihidupkan atau diberi kesan hidup oleh dalang. Sementara itu, di dalam Tari Golek Menak penari selaku wayang golek harus mampu melakukan gerak-gerak seperti wayang/boneka golek, yang di dalam bergerak itu penari harus tetap luwes, tidak kaku, sebagaimana boneka/wayang golek.

Dalam melakukan hal tersebut, penari masih tetap harus menjiwai filsafa Joged Mataram yang terdiri atas sawiji (konsentrasi), greget (bersemangat), sengguh (percaya diri), dan ora mingkuh (pantang menyerah). Di sini berlaku kata-kata hanjoged golek dan bukan golek hanjoged. Jadi, titik beratnya ada pada tariannya, bukan pada goleknya (Dewan Ahli Yayasan Siswo Among Bekso, 1981: 58). Diperlukan suatu pemahaman tentang kaidah-kaidah yang harus diikuti secara jelas. Hal itu sangat diperlukan oleh penari agar di dalam melakukan aktivitas Tari Golek Menak dapat menyatu dengan peran yang dibawakan, mampu menyatu dengan tubuh dan jiwanya, sehingga dapat menjadi sikap kepenarian yang akan menghasilkan gerak secara instinktif, tidak dibuat-buat.

Suharto (1991: 42) mengatakan bahwa pada tingkat tertentu, sewaktu seseorang sedang menari, terjadi sesuatu kemungkinan bahwa ia beralih menjadi sesuatu yang lain. Proses tersebut dapat dipandang sebagai proses transformasi. Tidak ada pretensi apa pun, keinginan apa pun, semuanya demi peran yang dibawakan. Keberhasilan bagi seorang penari menurut para guru tari di Kraton Yogyakarta adalah sebagai berikut. 
"Seseorang dianggap sudah "njoged" (menari) apabila dia menari dengan penuh disiplin, konsentrasi, motivasi, dan dedikasi. Mereka punya idiom yang berlaku terhadap seorang penari yang belum terisi jiwanya dengan istilah "isa njoged ............. nanging durung ngerti joged", sehingga belum mampu melihat nuansa antara "anjoged" (menari) dan "jogedan" (menari-nari)" (Wibowo, 1981: 105-107).

Setiap penari di dalam melakukan aktivitas kepenariannya harus selalu didasari oleh kebutuhan karakter yang dibawakan, tanpa dipengaruhi oleh tendensi pribadi yang ingin dimunculkannya. Itu sebuah tuntutan yang wajar dalam bidang pemeranan. Tuntutan tersebut mengandung konsekuensi bagi penari Golek Menak agar melakukan latihan secara teratur dan tekun, sehingga dapat merasakan setiap ruas persendian yang dimilikinya. Dengan demikian, harapan untuk mencapai gerak secara instinktif sesuai kebutuhan karakter akan terwujud.

Secara anatomis disebutkan bahwa pada saat seseorang menarik nafas maka rongga dada akan membesar, pengangkatan iga-iga, kontraksi sekat rongga badan melengkung ke atas, paru-paru mengikuti pelapangan rongga dada. Pada saat menghembuskan nafas akan terjadi kekenyalan dinding dada dan paru-paru menyempit, pada waktu itu iga-iga menurun kembali (Raven P. Chr., 1983: 32). Sementara itu, Usin (1984: 15) mengatakan bahwa waktu menarik nafas, rongga dada dibesarkan, gerakan tulang rusuk ke atas, menyebabkan tulang dada terdorong ke muka. Sewaktu menghembuskan nafas tulang rusuk turun, sehingga rongga dada menjadi sempit.

Dari sistem kerja alamiah menarik dan menghembuskan nafas tersebut didapatkan gambaran bahwa antara cara pernafasan dan torso, keduanya menyatu secara alamiah. Artinya, seseorang yang sedang bernafas akan menimbulkan akibat gerak pada torso. Dengan kata lain, timbulnya gerakan pada torso adalah akibat dari proses bernafas. Kedua aktivitas itulah akhirnya dipakai sebagai ciri yang harus dilakukan oleh setiap penari ketika menarikan Tari Golek Menak.

Hal di atas dimaksudkan bahwa unjal ambegan (cara pernafasan) yang dipadukan dengan akibat sampingnya (gerak torso) dijadikan aspek estetik yang harus dilakukan oleh penari setiap memulai dan melakukan motif gerak. Keduanya menjadi bagian yang tidak dapat berdiri sendiri. Seorang penari yang sedang menarikan Tari Golek Menak bisa tampak kurang greget disebabkan mereka hanya menggerakkan bahu. Padahal, bahu yang bergerak ini akibat dari gerak torso yang diakibatkan oleh cara penari menarik nafas atau unjal ambegan.

Di dalam tari klasik gaya Yogyakarta, pengambilan nafas ini sangat diperlukan sebagai sikap awal sebelum menari. Bagi seorang penari tari klasik gaya Yogyakarta, sebelum melakukan aktivitas gerak, seorang penari harus menemukan deg (sikap badan) yang baik dengan awalan pengambilan nafas. Sikap badan itu sangat terkait dengan posisi torso setelah pengambilan nafas. Gerak torso merupakan gerakan yang dihasilkan setelah seseorang menarik nafas, itu akan berakibat tulang rusuk menaik (iga kaunus), tulang punggung berdiri (ula-ula ngadeg), tulang belikat datar (enthong-enthong wrata), dada membusung (dhadha mungal), dan perut kempis (weteng nglempet). Setelah menemukan sikap tubuh yang demikian, penari harus merasakan sikap tersebut, sehingga pada saat melepaskan nafas, itu tidak mempengaruhi sikap yang telah ditemukannya. Demikian juga, penari harus mampu menghilangkan rasa ketegangan, sehingga tampak luwes dan semeleh.

Jika dalam tari klasik pengambilan nafas dipakai sebagai awal membentuk sikap badan ( $\mathrm{deg}$ ), di dalam Tari Golek Menak pengambilan nafas dan akibat terhadap gerak torso dijadikan elemen estetik yang harus tampak. Artinya, seorang penari harus betul-betul mampu memadukan keduanya menjadi bagian aktivitas gerak yang harus dikuasai. Yang menjadi masalah adalah bagaimana mendapatkan gerak torso dengan cara pernafasan yang tepat agar tarian menjadi indah atau mengandung muatan estetika.

Sebagaimana telah diuraikan sebelumnya, kedua aktivitas pada gerak torso dan cara pernafasan saling mengait, tidak dapat berdiri sendiri. Artinya, cara pernafasan akan sangat mempengaruhi keluaran pada gerak torso. Keluaran pada gerak torso akan menjadi baik apabila seseorang mampu menerapkan pola pernafasan antara yang dihirup dan dikeluarkan dan penerapannya sesuai dengan kebutuhan karakter.

Ada tiga faktor yang saling mengait akibat dari unjal ambegan, yaitu pertama, gerak torso harus selaras dan baik, kedua, untuk menghasilkan gerak torso yang baik sangat bergantung pada atau ditentukan oleh unjal ambegan (cara pernafasan), dan ketiga, perpaduan di antara keduanya harus selaras dengan karakter yang dimainkan.

Sebagaimana telah diuraikan di atas, antara aktivitas gerak torso dan cara pernafasan saling mengait, tidak dapat berdiri sendiri. Cara pernafasan sangat mempengaruhi gerak torso. Gerak torso akan menjadi baik apabila mampu menerapkan pola pernafasan, baik mengambil nafas dan mengeluarkan nafas diterapkan sesuai dengan kebutuhan karakternya. Ini artinya, aktivitas gerak tersebut bersifat individual yang didasari oleh tuntutan masing-masing karakter yang dimainkan. Memang, secara tepat bagaimana seorang penari dapat melakukan gerak torso dan cara pernafasan, sehingga geraknya dapat dikatakan "hidup", teramat rumit untuk dideskripsikan. Pada hakekatnya hal tersebut sangat terkait dengan kemampuan individu dan kedisiplinan individu dalam berlatih.

Menurut paparan para pelaku pembakuan Tari Golek Menak dapat dinyatakan bahwa pada saat menarik nafas posisi torso meregang ke atas, pada saat itu "daya hidup" Tari Golek Menak muncul yang selanjutnya diratakan ke seluruh bagian tubuh, dan pada saat mengeluarkan nafas aktivitas gerak harus semeleh 
(tidak tegang). Pada saat menghirup dan mengeluarkan nafas tidak boleh melakukan secara penuh di rongga paru-paru, karena apabila pengambilan nafas secara penuh di paru-paru akan mengakibatkan posisi torso menjadi tegang. Demikian pula, pada saat mengeluarkan nafas tidak boleh dikeluarkan semua (di paru-paru masih ada udara) karena apabila nafas dikeluarkan semuanya akan berakibat sikap torso menjadi kendor. Untuk merasakan aktivitas itu, diperlukan latihan yang teratur dan tertib.

Teknik "unjal ambegan" merupakan aktivitas yang harus dilakukan di setiap penari melakukan aktivitas gerak Tari Golek Menak. Artinya, cara pernafasan merupakan bagian yang sangat erat dan mengait di setiap penari melakukan aktivitas gerak, pada saat mengawali, proses bergerak, maupun saat diam. Hal tersebut merupakan ciri Tari Golek Menak yang dapat menjadi daya hidup dan membantu dalam mengekspresikan karakter.

Dalam menggerakkan torso pun harus diawali oleh "unjal ambegan" agar geraknya menjadi baik menyerupai boneka kayu, walaupun harus tetap menjaga keluwesannya. Untuk itu, diperlukan pengaturan yang dapat dibantu dengan irama gending dan irama tarinya. Penerapannya bergantung pada kemampuan penari. Artinya, masing-masing penari dapat melakukan aktivitas tersebut sesuai dan selaras dengan kemampuan dan karakter yang dibawakan. Dapat kiranya dijabarkan bahwa gerak menaik bersamaan dengan menarik nafas, gerak menurun bersamaan dengan mengeluarkan nafas. Pada proses tersebut nafas tetap masih tersisa pada paru-paru agar masih tetap terjaga kondisi kepenariannya untuk tidak mengendor.

\section{Perbedaan Pola Nafas Tari Klasik dan Tari Golek Menak}

Telah dipaparkan terdahulu bahwa Tari Golek Menak mengacu pada wayang golek menak (boneka kayu), sementara tari klasik mengacu pada wayang kulit purwa. Oleh karena itu, cara pernafasan dan gerak torso pada Tari Golek Menak berbeda dengan tari klasik. Hal yang sama antara tari klasik dan Tari Golek Menak tentang pola nafas adalah pada pengambilan sikap badan $(d e g)$. Sebelum melakukan tugas kepenarian, seorang penari gaya Yogyakarta harus dapat memposisikan sikap badan (deg) dengan cara mengambil nafas dan mengeluarkannya tanpa merubah sikap badan yang sudah ditemukan pada saat mengambil nafas. Sementara, untuk Tari Golek Menak, cara pernafasan menjadi bagian dari teknik yang harus dikuasai dan dilakukan pada saat penari mulai gerak, melakukan aktivitas gerak, dan pada saat diam.

Pada Tari Golek Menak teknik gerak torso dan cara penafasan berbeda dengan yang ada pada tari klasik. Pada Tari Golek Menak pola nafas lebih ditonjolkan, pada tari klasik tidak. Di dalam Tari Golek Menak gerak torso mempunyai kebebasan gerak, didasarkan atas pendapat keenam narasumber yang mempunyai pandangan yang sama terhadap kebebasan gerak torso tersebut. Namun, pengertian bebas di situ tetap berpijak pada karakter yang dibawakannya, yang dalam hal ini setiap karakter mempunyai ciri gerak yang berbeda.

Dalam hal bergerak pun tidak dibuat-buat, melainkan menjadi gerak yang bersifat instinktif, dan harus menjadi sikap bagi setiap penari, sehingga dapat menyatu dengan karakter yang dibawakan. Untuk itu, setiap penari harus mempelajari karakter tokoh yang dibawakan, harus mampu menyatukan teknik, penjiwaan, dan karakternya agar dapat menjadi "urip" (indah). Sementara itu, pada tari klasik kondisi torso tidak dieksplorasi menjadi bagian dari aktivitas gerak.

Karena unsur gerak Tari Golek Menak banyak diambil dari tari klasik, maka penari yang akan belajar Tari Golek Menak diharuskan berangkat dari tari klasik agar tetap terjaga keluwesannya. Hal itu didasari oleh kekhawatiran apabila seseorang langsung belajar Tari Golek Menak, yang menjadi prioritas perhatiannya adalah kaku-kakunya.

\section{E. Penutup}

Keberadaan Tari Golek Menak dalam khasanah tari gaya Yogyakarta telah menambah alternatif pertunjukan di luar cerita Mahabarata dan Ramayana. Karena Tari Golek Menak merupakan hasil adaptasi dari wayang golek, maka karakter geraknya pun terinspirasi dari gerak-gerak wayang golek yang sedang dimainkan oleh dalang.

Gerak unjal ambegan merupakan gerak yang menjadi ciri dalam Tari Golek Menak. Pada setiap melakukan aktivitas gerak torso atau lainnya tidak dapat dipisahkan dengan unjal ambegan atau cara pernafasan. Keduanya saling mengait dan memadu secara mengikat. Sementara itu, penerapannya bergantung pada kemampuan penari (dibebaskan) tetapi tetap dibingkai oleh karakter dan aturan yang disepakati.

Agar dalam menggabungkan aktivitas gerak torso dengan cara pernafasan dapat menjadi baik, diperlukan latihan yang kontinu, disiplin, dan dirasakan tingkat perubahannya pada masing-masing gerak yang dilakukan. Dengan demikian, hal itu dapat menjiwai serta sesuai dengan karakter yang dibawakannya. Di samping itu, penguasaan teknik gerak tari klasik dapat membantu, karena banyak teknik gerak tari klasik yang digunakan pada Tari Golek Menak.

\section{Daftar Pustaka}

Dewan Ahli Yayasan Siswo Among Bekso. 1981. Kawruh Joged Mataram. Yogyakarta: Yayasan Siswo Among Bekso.

Raven P. Chr. 1983. Atlas Anatomi (Terj. Ahmad Ramali dan Hendra T. Laksman). Jakarta: Djambatan. 
Suharto, Ben. 1991. “Tari dalam Pandangan Kebudayaan” dalam Jurnal SENI Edisi Perdana. Yogyakarta: BP ISI.

Usin, Jos. 1984. Pernafasan untuk Kesehatan. Bandung: PO Box 86

Wibowo, Fred. 1981. Mengenal Tari Klasik Gaya Yogyakarta. Yogyakarta: Dewan Kesenian Propinsi Daerah Istimewa Yogyakarta.

Daftar Narasumber:

KRT Sasminto Dipuro (Alm.)

Bpk Sunartomo (KRT Condroradono)

Bagong Kussudiardjo (Alm.)

RM Dinu Satomo, BA., Ketua Yayasan Siswo Among Bekso Yogyakarta

R.M. Ywanjono, Ketua paguyuban Surya Kencana Yogyakarta

Bambang Pujaswara, S.S.T., M.Hum.dosen pada Jurusan Seni Tari ISI Yogyakarta. 